\title{
Prenatal MRI visualisation of the aortic arch and fetal vasculature using motion-corrected slice-to- volume reconstruction
}

\author{
David Lloyd ${ }^{1,2^{*}}$, Bernhard Kainz ${ }^{2}$, Joshua F van Amerom², Maelene Lohezic ${ }^{2}$, Kuberan Pushparajah ${ }^{1,2}$, \\ John M Simpson', Christina Malamateniou², Joseph V Hajnal ${ }^{2}$, Mary Rutherford², Reza Razavi ${ }^{2,1}$ \\ From 19th Annual SCMR Scientific Sessions \\ Los Angeles, CA, USA. 27-30 January 2016
}

\section{Background}

The antenatal diagnosis of vascular abnormalities such as coarctation of the aorta may allow for more timely provision of what can be life-saving postnatal care. Fetal MRI offers the potential to compliment conventional antenatal assessment of the extracardiac vasculature, which can be difficult to assess by ultrasound.

\section{Methods}

Using overlapping multi-slice 2D single-shot fast spin echo sequences (Philips, $1.5 \mathrm{~T}, \mathrm{TR}=15000 \mathrm{~ms}$, TE $=$ $100 \mathrm{~ms}$, flip angle $=90$ degrees, voxel size $=350 \times 350$ $\mathrm{mm}$, slice thickness $=2.5 \mathrm{~mm}$, SENSE factor $=2$, partial Fourier-factor $5 / 8$, slice duration $468 \mathrm{~ms}$ ) in a fetus at 36 weeks gestation, we applied a novel GPU accelerated super-resolution algorithm for slice-volume registration to the oversampled data to compensate for fetal movements between slices.

\section{Results}

A 3D dataset was generated with an isotropic voxel size of $0.4 \mathrm{~mm}$ for visualisation of fetal structures. Using this we were able to clearly show the relationship of the great vessels, demonstrating hypoplasia of the aortic arch and a
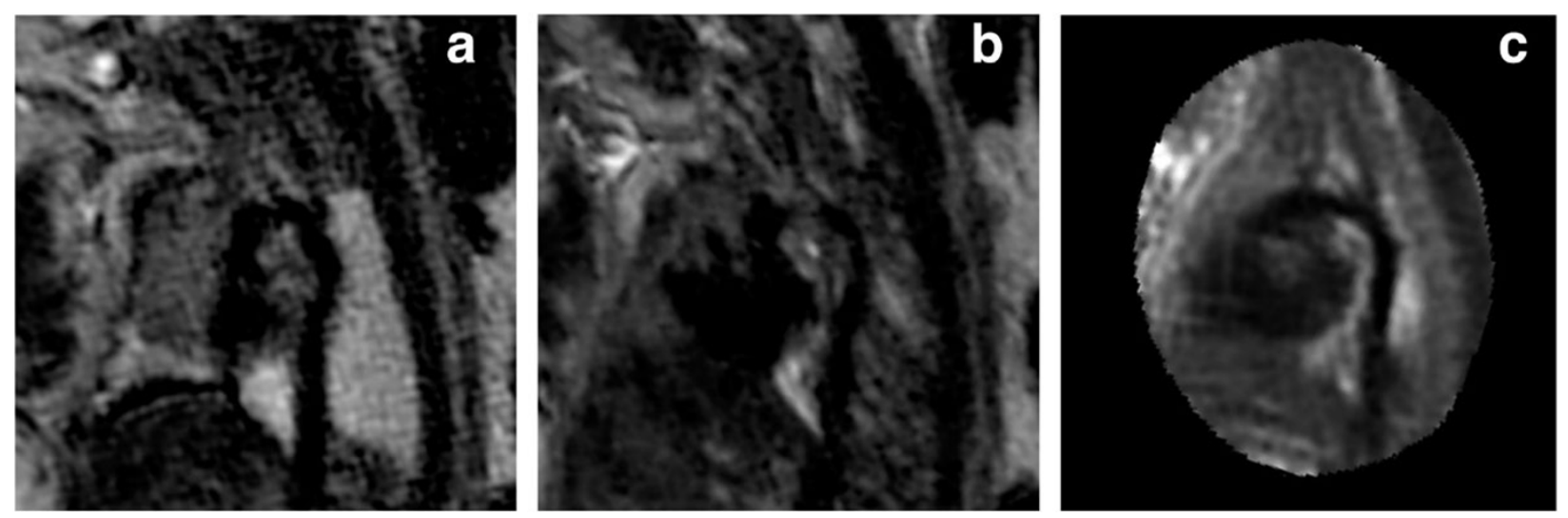

Figure 1 The aortic and ductal arches in a 36 weeks fetus as visualised from a.) a single-shot fast spin echo MRI image; b.) a (motioncorrupted) 3D volume derived from the concomitant multi-slice stack; and c.) the resultant 3D volume after application of a GPU accelerated super-resolution algorithm for slice-volume registration (using multiple stacks). In the final image, the hypoplastic aortic arch is now clearly visualised superior to the dominant ductal arch.

'Evelina Children's Hospital, London, United Kingdom

Full list of author information is available at the end of the article 
high risk of coarctation. Following delivery, critical coarctation of the aorta was confirmed. The baby went on to have surgical repair in the neonatal period.

\section{Conclusions}

Uncontrolled fetal movement represents a major challenge to more widespread adoption of fetal cardiovascular MRI. Automated motion-corrected 3D volume reconstructions could greatly increase the diagnostic utility of antenatal MRI in the future.

\section{Authors' details}

${ }^{1}$ Evelina Children's Hospital, London, United Kingdom. ${ }^{2}$ King's College

London, London, United Kingdom.

Published: 27 January 2016

doi:10.1186/1532-429X-18-S1-P180

Cite this article as: Lloyd et al:: Prenatal MRI visualisation of the aortic arch and fetal vasculature using motion-corrected slice-to-volume reconstruction. Journal of Cardiovascular Magnetic Resonance 2016 18(Suppl 1):P180

Submit your next manuscript to BioMed Central and take full advantage of:

- Convenient online submission

- Thorough peer review

- No space constraints or color figure charges

- Immediate publication on acceptance

- Inclusion in PubMed, CAS, Scopus and Google Scholar

- Research which is freely available for redistribution

Submit your manuscript at www.biomedcentral.com/submit 